lan C. Bickle, MB,BCh,BAO, FRCR

Department of Radiology

RIPAS Hospital

Bandar Seri Begawan

Brunei
Correspondence: Dr. lan C. Bickle

Consultant Radiologist

Department of Radiology

RIPAS Hospital

Bandar Seri Begawan BA1710

Negara Brunei Darussalam

Phone: +673224 2424

Fax: +6732242690

Email:firbeckkona@gmail.com

The author declared that this represents original material that is not being considered for publication or has not been published or accepted for publication elsewhere, in full or in part, in print or electronic media; that the manuscript has been read and approved by the author, that the requirements for authorship have been met by the author, and that the author believes that the manuscript represents honest work.

Disclosures: The author signed disclosures that there are no financial or other (including personal) relationships, intellectual passion, political or religious beliefs, and institutional affiliations that might lead to a conflict of interest.

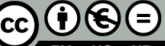

Creative Commons (CC BY-NC-ND 4.0)

Attribution - NonCommercial - NoDerivatives 4.0 International

\section{Intracranial Complications of Acute Sinusitis on Brain CT}

This 35-year-old woman presented to a peripheral hospital Accident and Emergency department in a moribund state. She was intubated, stabilized and transferred urgently to a tertiary centre. She had attended the hospital in the prior week with a diagnosis of sinusitis.

An urgent $C T$ brain was requested by the attending $A$ and $E$ officer which was undertaken on the basis of her low Glasgow coma scale (GCS). The paranasal sinuses were partially visualised on this investigation.
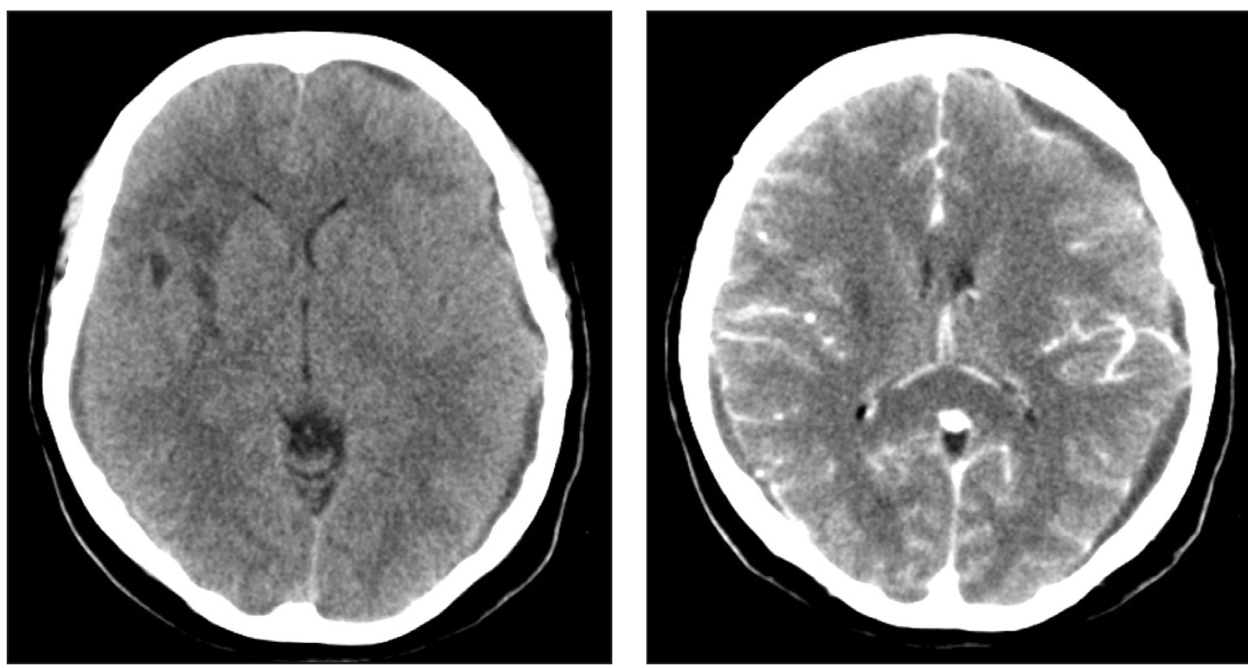

Figure 1 A. Axial CT Brain (non-contrast): thin bilateral subdural collections. Low attenuation in the inferior right temporal lobe and externa internal capsule suggestive of an acute infarct. B. Axial CT Brain (with contrast): enhancing bilateral subdural collections in keeping with empyemas.

Acute bacterial rhinosinusitis is a common disease presenting to both general practitioners and ENT surgeons. It is on the most part short-lived in duration responding to antibiotics and symptomatic medications. Rarely it may be associated with severe life threatening complications, in the form of intra-orbital extension or even less so intracranial complications. These typically occur in the pediatric and young adult population. ${ }^{1}$

Cross-sectional imaging plays an essential role in the assessment of this small sub-set of patients and is largely and almost always in the first instance with $\mathrm{CT}^{2}$ Computed Tomography is broadly available even out of standard working hours and facilitates the review of potential intracranial complications and thereby guide neurosurgical management. Given that a proportion of the paranasal sinuses are always visualised on a CT brain it is an important review area especially in patients with sepsis. 


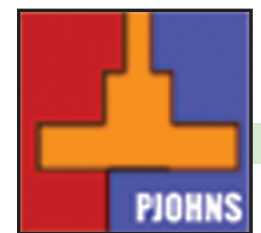

\section{FROM THE VIEWBOX}

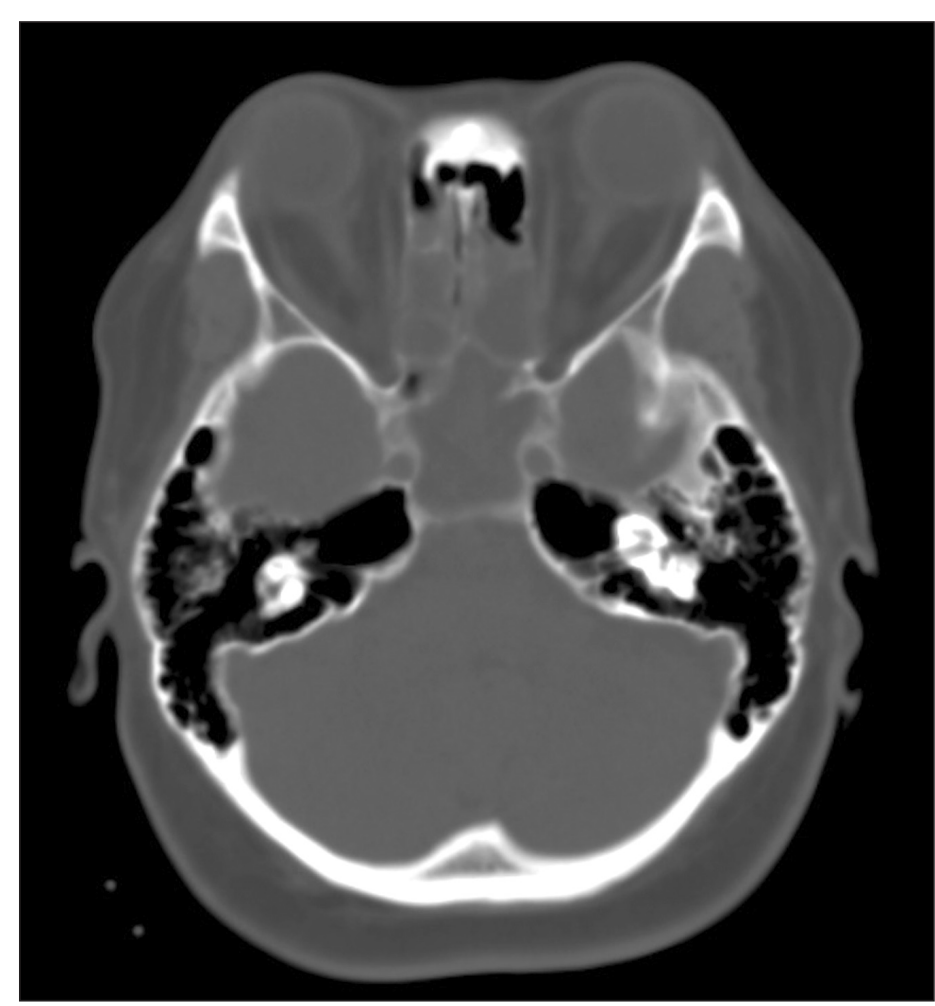

Figure 2. Axial CT Brain: The ethmoid and sphenoid sinuses are opacified with fluid. No bony destruction.

There are a number of well recognized intracranial complications of acute rhinosinusitis which include; meningitis, cerebral abscess, subdural empyema, cavernous sinus and dural venous thrombosis. ${ }^{3}$ Additional sequelae from the intracranial infection may result such as arterial territory cerebral infarction, ventriculitis and hydrocephalus.

Those patients in whom intracranial extension occurs often demonstrate bony destruction of the sinuses on imaging. Disease involving the frontal sinus is typically associated with intracranial complications, through foci of bony dehiscence or osteomyelitis involving the floor of the anterior cranial fossa. ${ }^{3}$

In this case, the patient presented in a moribund state due to severe intracranial complications following failed treatment in the community. The initial CT imaging identified subdural collections (Figure 1a and 1b) as well as pan-sinusitis (Figure 2) and the suggestion of an arterial territory infarct (Figure 1a). The frontal sinus however was not involved in this instance.

A complete CT study of the paranasal sinuses (with a dedicated paranasal sinuses protocol) is merited including isotropicreconstructions to review the bony integrity and aid the planning of ENT surgical intervention. An MRI brain if available would eloquently confirm the CT findings including confirmation of the acute parietal lobe infarct. ${ }^{4}$

Neurosurgical drainage of the subdural empyemas was undertaken. Furthermore, functional endoscopic sinus surgery (FESS) was also performed with drainage of a large volume of pus from the sphenoid, ethmoidal and right maxillary sinuses. ${ }^{4}$

This case demonstrates intracranial complications are not an entity unique to the paediatric population. When caring for patients with acute sinusitis always have a high index of suspicion for these potential complications and have a low threshold for engagement with radiology colleagues for imaging if concerned.

\section{REFERENCES}

1. Sultész $M, C$ cákányi Z Majoros T, Farkas Z Katona G. Acute bacterial rhinosinusitis and its complications in our pediatric otolaryngological department between 1997 and 2006. Int J Pediatr Otorhinolaryngol. 2009 Nov;73(11):1507-12. DOI: 10.1016/j.ijporl.2009.04.027 PMID: 19500861

2. Dankbaar JW, van Bemmel AJM, Pameijer FA. Imaging findings of the orbital and intracranial complications of acute bacterial rhinosinusitis. Insights Imaging. 2015 Oct; 6(5): 509-518. DOI: 10.1007/s13244-015-0424-y_PMCID: PMC4569601

3. Osborn MK, Steinberg JP. Subdural empyema and other suppurative complications of paranasal sinusitis. Lancet Infect Dis. 2007 Jan;7(1):62-7. DOI: : 10.1016/S1473-3099(06)70688-0 PMID: 17182345

4. Bickle IC. Intracranial complications of acute sinusitis. Case rID: 45559. Created 30 May 2016 in Radiopaedia.org @2005-2017. [Cited 2017 June 13] Available from: https://radiopaedia.org/ cases/intracranial-complications-of-acute-sinusitis. 